\title{
PM Halbach Arrays in Motors: Loss Reduction and Performance Improvements
}

\author{
Ahmed Hebala *, Stefano Nuzzo ${ }^{* * *}$, Peter H. Connor ${ }^{*}$, Paolo Giangrande * , Chris Gerada *, \\ Michael Galea ${ }^{* * * * *}$ \\ ${ }^{*}$ Power Electronics, Machines and Control (PEMC), University of Nottingham, United Kingdom \\ ** Department of Engineering Enzo Ferrari within University of Modena and Reggio Emilia, Italy \\ ${ }^{* * *}$ Key Laboratory of More Electric Aircraft Technology of Zhejiang Province, University of Nottingham, Ningbo, China
}

\begin{abstract}
Halbach array configurations represent a common choice in high-performance electrical machines, since a stronger magnetic field is generated for the same Permanent Magnet (PM) volume. Hence, higher torque is developed, and the power density is enhanced. This paper investigates methodologies for reducing the PM losses in Halbach arrangements. A high power density propulsion motor is considered as a case-study and by using Finite Element (FE) software, sensitivity analyses are performed on the main design parameters. Strategies for loss reduction and performance improvements, in terms of torque ripple, total harmonic distortion, efficiency and power density, are investigated and proposed. The effectiveness of axial and radial segmentations, PM edge shape, and semi-magnetic slot wedges are evaluated. Finally, recommendations are made for designing a PM Halbach array.
\end{abstract}

Index Terms - Halbach PM array, PMSM, Eddy-Current losses, Electrical Machines.

\section{INTRODUCTION}

In recent years, there has been a growing and continued demand for high efficiency and high specific power electrical machines, particularly for transport applications [1]. Permanent Magnet Synchronous Machines (PMSMs) well suit these requirements when compared to other machine topologies [2], [3]. Yet, PMSMs, especially when equipped with PMs mounted on the external profile of the rotor (i.e. surface-mounted PMSMs), can feature a high torque ripple. The torque ripple, in turn, can cause high noise and vibration levels and it can produce resonance phenomena in the mechanical and control systems. To mitigate and significantly reduce these effects, PM Halbach arrays (HBAs) have been proposed in electric motors and generators [4].

The HBAs can be arranged into a curved surface, as reported in Fig.1, which shows a five-stage configuration. In the example of Fig. 1, the HBA layout is achieved by shifting the direction of magnetisation between adjacent PMs by $45^{\circ}$. HBAs have formerly been proposed in traction motors for electric vehicles and aerospace traction and propulsion [5]-[7]. The HBA enhances the magnetic field on one side of the array and minimises it on the other side. In this case these effects are seen on the air-gap and rotor back iron sides of the HBA, respectively. Consequently, power density and efficiency are improved by increasing the produced torque and lowering the overall machine volume and torque ripple.

Nevertheless, surface-mounted PMSMs tend to experience elevated eddy current losses even when HBAs are used, especially at higher operating frequencies. Moreover, to improve the flux weakening capability of PM motors, concentrated tooth coil winding is used [8], which further increases the eddy current loss in the magnets. Certain measures may be implemented to keep these losses within a controllable range.

As a case study, a propulsion motor for an 8-12 passenger aircraft is presented for this study. The power requirement for this motor is at least $560 \mathrm{~kW}$ to drive the propeller of an aircraft such as Cessna Caravan [9].

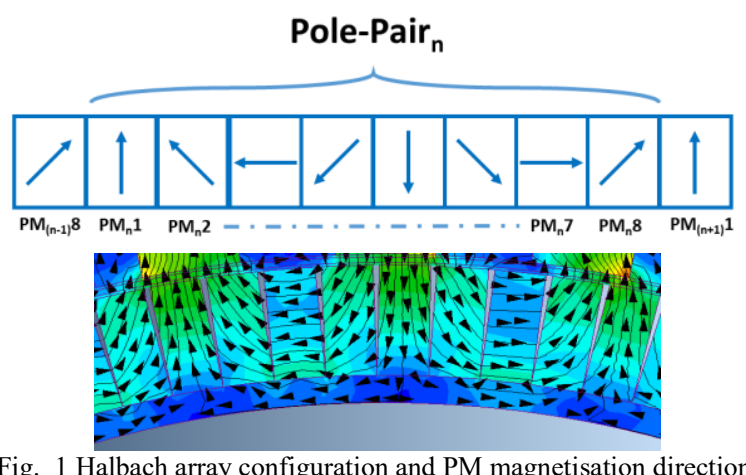

Fig. 1 Halbach array configuration and PM magnetisation direction.

\section{REFERENCE MACHINE DESCRIPTION}

The main design features of this motor are defined as a stator having four three-phase concentrated windings located within 36 slots. The rotor has 30 poles arranged as a five-stage HBA. The motor is designed to operate at steady-state conditions at $2000 \mathrm{rpm}$ speed and an output power equal to $752.1 \mathrm{~kW}$ for a driving torque of $3591 \mathrm{Nm}$. The efficiency is $95.3 \%$, with the PM losses the highest component loss of $31.5 \mathrm{~kW}$ that is more than $85 \%$ of the motor's total losses. The design process of such a motor is fully reported in [10]. Windage and friction losses are neglected, and rotor loss is less than $100 \mathrm{~W}$. The focus of this paper is optimising the HBA parameters to minimise these losses to increase the efficiency up to $98 \%$, without the need for an advanced rotor cooling system that might be unfeasible in this application. The full motor parameters and dimensions are listed in Table I. The minimum angular sector of the motor, i.e. 1/6-th, necessary to display all the main features of the machine is shown in Fig. 2.

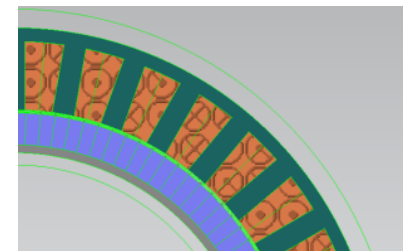

Fig. 2 A $1 / 6$ th of the cross-section of the original machine design. 
TABLE I

ORIGINAL MACHINE PERFORMANCE INDICATORS

\begin{tabular}{|c|c|c|c|}
\hline Parameter & Value & Parameter & Value \\
\hline Average torque (Nm) & 3591 & Stator losses (W) & 1.4 \\
\hline Torque ripple (\%) & 1.27 & PM losses (W) & 31.5 \\
\hline Output power (kW) & 752.1 & Cu losses (W) & 4.4 \\
\hline $\begin{array}{c}\text { Power density } \\
\text { (kW/kg) }\end{array}$ & 7.52 & $\begin{array}{c}\text { Stator outer radius } \\
\text { (mm) }\end{array}$ & 231.5 \\
\hline Efficiency (\%) & 95.3 & $\begin{array}{c}\text { Stator inner radius } \\
\text { (mm) }\end{array}$ & 180 \\
\hline $\begin{array}{c}\text { Peak phase current } \\
\text { (A) }\end{array}$ & 465 & $\begin{array}{c}\text { Airgap thickness } \\
\text { (mm) }\end{array}$ & 2 \\
\hline $\begin{array}{c}\text { Peak current density } \\
\text { (A/mm2) }\end{array}$ & 10.7 & PM thickness (mm) & 20 \\
\hline $\begin{array}{c}\text { Number of turns per } \\
\text { coil }\end{array}$ & 7 & $\begin{array}{c}\text { Rotor back iron width } \\
\text { (mm) }\end{array}$ & 5 \\
\hline $\begin{array}{c}\text { Number of 3-phase } \\
\text { groups }\end{array}$ & 4 & $\begin{array}{c}\text { Motor stack length } \\
\text { (mm) }\end{array}$ & 151 \\
\hline
\end{tabular}

\section{STUdiEd CONFIGURATIONS}

As stated earlier, the ohmic losses induced in the rotor PMs account for more than $85 \%$ of the motor's overall losses. The strategy of this paper is to primarily decrease these losses and secondly to improve the overall performance of the motor. Hence, the torque ripple, total harmonic distortion (THD), and power density, etc, will be evaluated along with the different proposed studies. The approach adopted here is to not fundamentally change the design of the motor i.e., no change to the slot-pole combination, winding arrangement, or the stator's main geometry. Rather, the target will be pursued through the PM arrangement and shape, with one exception at study 'E' (see Section III.E) where a semi-magnetic wedge (SM$\mathrm{W}$ ) is used at the slot openings. Therefore, unless explicitly mentioned all machine parameters listed in Table I will remain the same throughout these studies and will be referred to as original machine design (OMD).

The first study ' $A$ ' will implement a tangential segmentation to each PM segment. In study ' $\mathrm{B}$ ', the magnets will be segmented along the axial direction. Then, in study ' $\mathrm{C}$ ', the PMs will be firstly changed from arcshaped to bricks [11], then the angular span Spm will be investigated. Study ' $\mathrm{D}$ ' will modify the PM tips that is near the airgap. Finally, in study ' $E$ ' the use of SM-Ws in the slots will be investigated.

\section{A. Study A: Tangential Segmentation}

As mentioned in Section II, the OMD has a 30-pole rotor with the magnets arranged as a five-stage HBA. Hence, each pole pair will consist of 8 segments resulting in a total of $30 \times 8=120$ magnets required to build the whole arrangement.

In study ' $A$ ' each segment will be divided in the tangential direction into 2 and then 3 sub-segments as shown in Fig. 3b Fig. 3c respectively. Each segment has a $3^{\circ}$ mechanical angular span in the OMD, while this value becomes $1.5^{\circ}$ for the 2 sub-segments study and $1^{\circ}$ for the 3 sub-segments one. The performance and losses breakdown are plotted in Fig. 4. The effectiveness of the method is clear, as the PM losses are reduced, with a maximum drop of $10.7 \%$ achieved. Nevertheless, this is minimal when compared to the predefined targets. In addition, there is an incremental decrease to the average torque and higher torque ripple is experienced with more segments, due to a slight increase to the air-gap flux density.

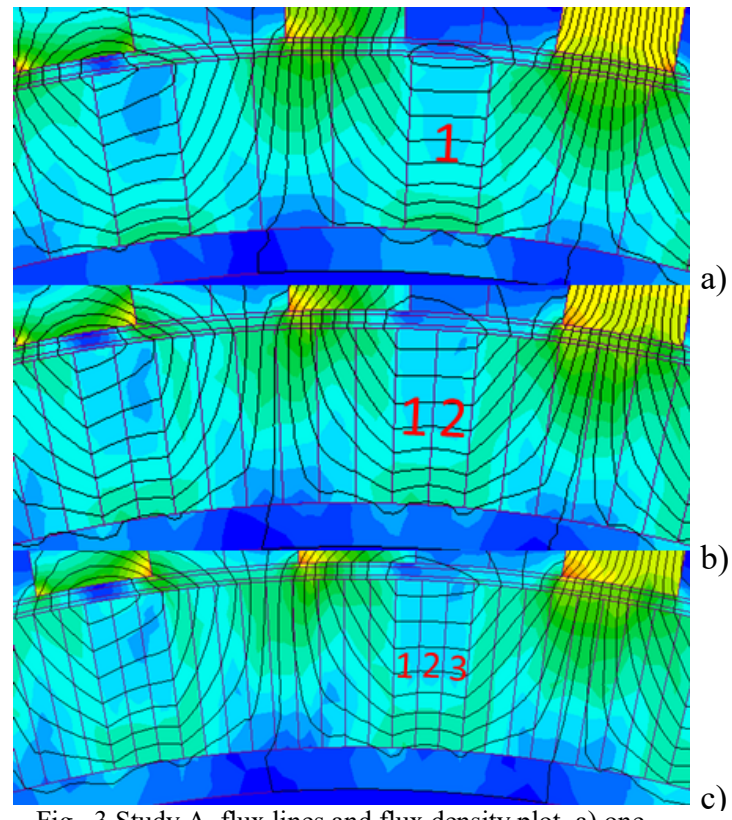

Fig. 3 Study A, flux lines and flux density plot, a) one tangential design, b) two sub-segments, c) three sub-segments.

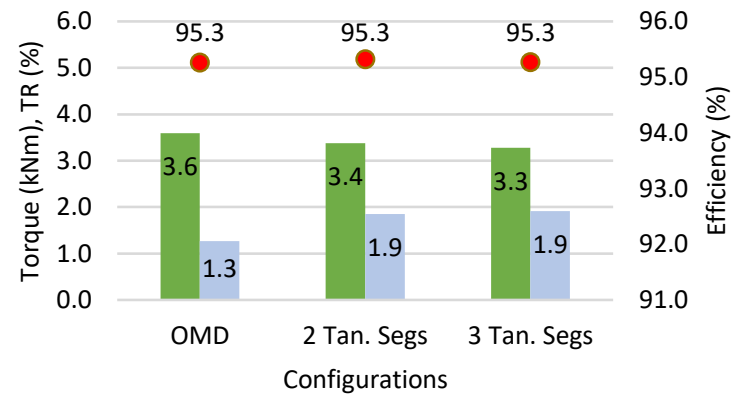

- Torque (kNm) - Torque Ripple(\%) Eff. (\%)

a)

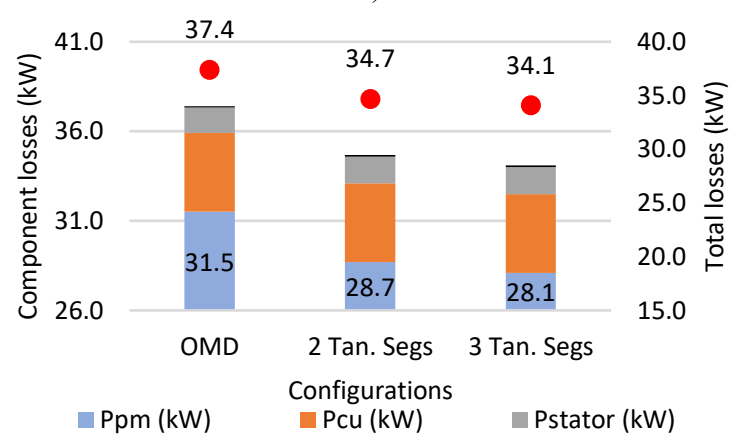

b)

Fig. 4 Study A, a) main performance features, b) loss breakdown.

\section{B. Study B: Axial Segmentation}

A similar approach to study ' $A$ ' is performed here, but with the segmentation being applied to each individual PM segment in the axial direction. This means that each PM segment has initially the same length as the motor, i.e. 151 $\mathrm{mm}$, so when for example 10 axial sub-segments are implemented, then their length will be $15.1 \mathrm{~mm}$. While this in an inherently 3D feature, a 3D FE analysis would be a time and computationally expensive procedure. Therefore 
in this paper, (1) is used to emulate the same effect of a 3D simulation into a 2D one [12]. Where the losses (PM resistivity) are proportional to this factor ' $F_{p m}$ '. In (1), ' $l$ ' is defined as the axial segment length, and ' $w$ ' is the width in the tangential direction per sub-segment.

$F_{p m}=\frac{3}{4} \frac{l^{2}}{l^{2}+w^{2}}$

To demonstrate the effect of this factor, a generalised study on varying either 1) the number of poles as in Fig. $5(a), 2)$ the motor stack length as in Fig. 5(b) and 3) the rotor radius as in Fig. 5(c) is presented.

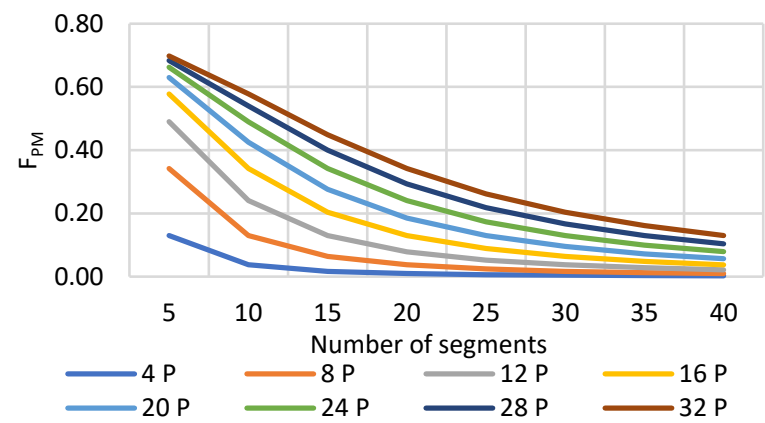

a)

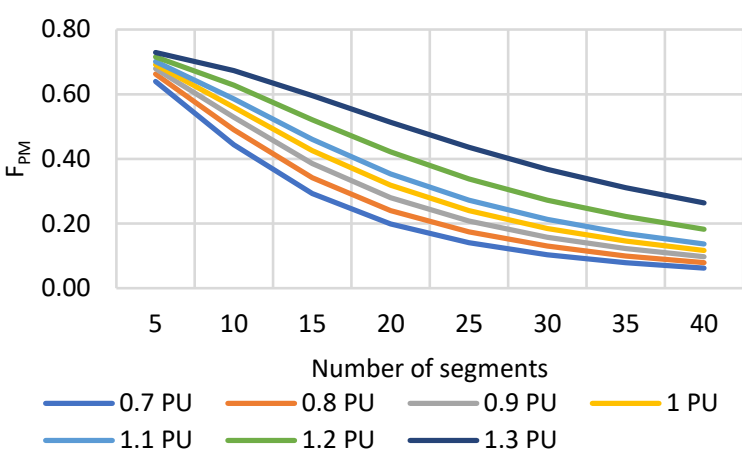

b)

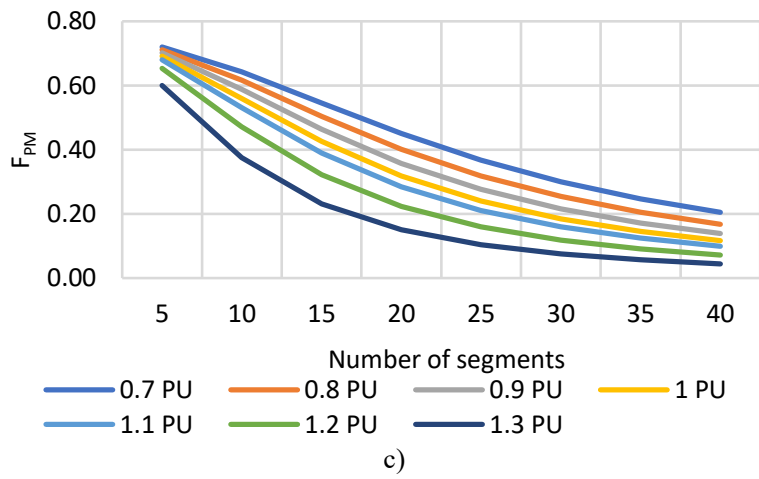

Fig. 5 Generalized study of axial segmentation factor, a) Axial Segmentation with varied pole number, b) Axial segmentation with varied stack length, c) Axial segmentation with varied rotor radius.

As illustrated in Fig. 5(a), this factor seems to be more effective for a lower number of poles for the same number of axial segments. For example, for given axial length (i.e. $151 \mathrm{~mm}$ ) and number of axial segments (i.e. 20), Fpm is equal to 0.01 , whereas it is equal to 0.18 for a 20 -pole motor. Similarly, the shorter the overall length of the motor, the more effective the segmentation. On the other hand, Fig. 5(c) informs on the fact that the segmentation is more efficient for higher rotor diameters.
However, recalling that the main objective of this work is that no major changes to the ODM design should be applied, the number of poles, motor axial length and rotor diameter are all fixed in this study. In particular, the number of sub-segments is ranged from 5 to 30 . The results reported in Fig. 6 show improvements in terms of efficiency, average torque, and output power. When 30 sub-segments are used, the PM losses are at $6 \mathrm{~kW}$, thus equal to $19 \%$ only of the OMD level. The torque ripple remains effectively the same as in the OMD.

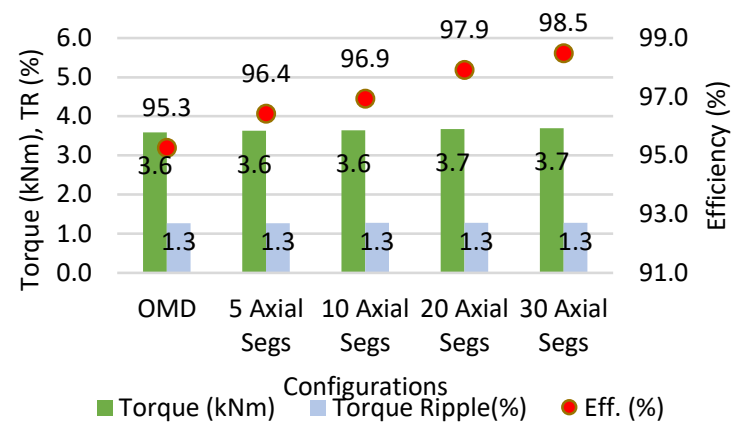

a)

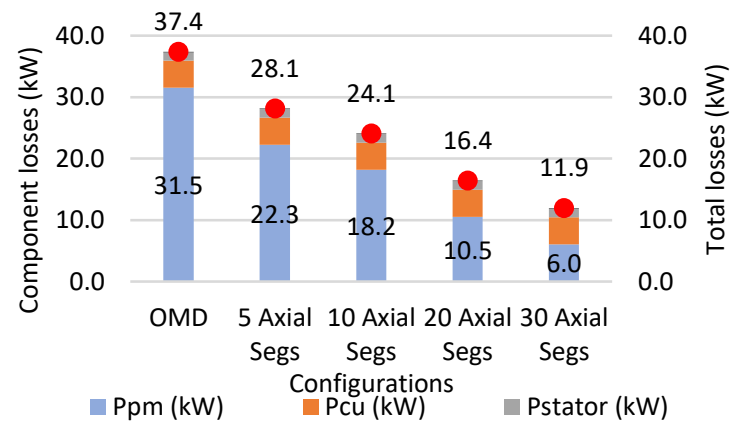

b)

Fig. 6 Study B, a) main performance features, b) losses breakdown.

\section{Study C: Edges and Pole Angle Span}

In this study, a comparison between PMs with arc shapes, as in the ODM, and PMs featuring parallel sides in the radial direction (i.e. bricks) is conducted. The pole angle (Spm) is varied from 1 p.u. to 0.7 p.u. in steps of 0.1 p.u., as qualitatively represented in Fig. 7 . The performance and loss breakdown are mapped in Fig. 8. This method can be quite effective in cutting the losses, even up to almost half, as in the case of an 0.7 Spm radial or parallel sections, which leads to an efficiency increase. Yet, this comes at the cost of much reduced average torque and output power, thus for a change of 0.1 p.u. in Spm with a radial section the power drops by almost $7 \%$. However, it also has the advantage of lower-cost since less material is required, as well as having the potential for more simple assembly and manufacturing.

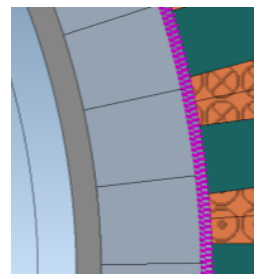

(a)

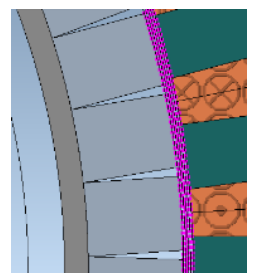

(b)

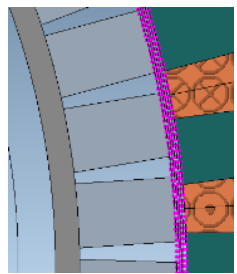

(c)
Fig. 7. PM a) Radial Sector, b) Parallel Section with 1 pu angle, c) Parallel Section with 0.75 pu angle. 


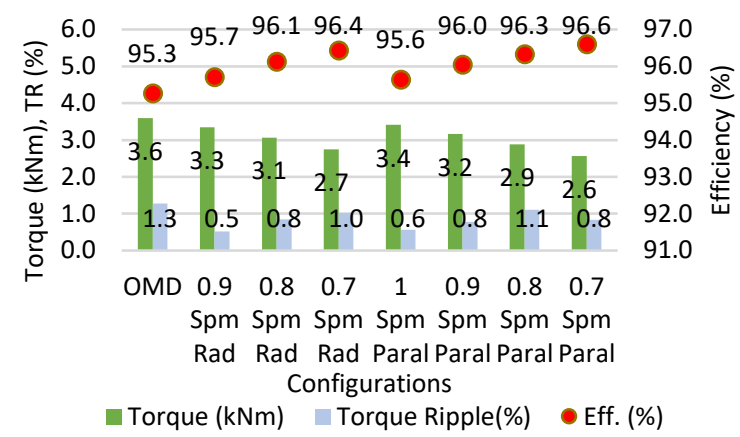

a)

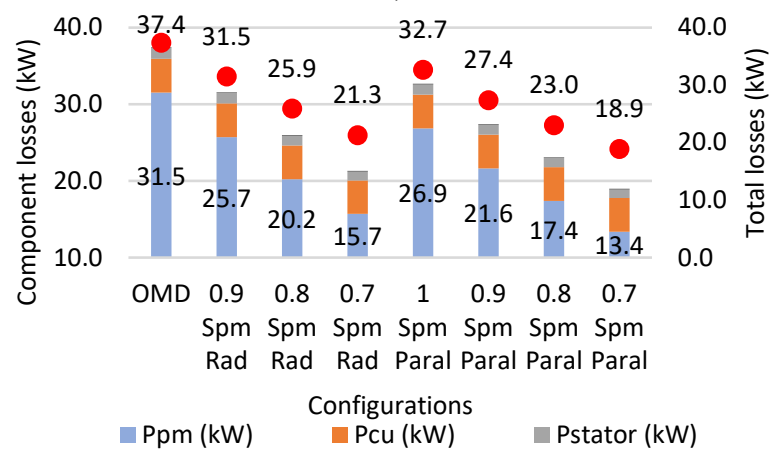

b)

Fig. 8 Study $\mathrm{C}$, a) main performance features, b) losses breakdown.

\section{Study D: PM Tips shaping}

Another way to manipulate the PM shape is by changing the PM tips. Two ways are proposed here. The first is called "centric based", where a circle of a certain diameter is placed along the radial axis of the PM segment and is to intersect with its centre, as shown in the top three sketches in Fig. 9. Similarly, two circles of a certain diameter are displaced from the tip edge by the same radius and intersect with the tips, by such an area of the PM is removed, as shown in the bottom three sketches in Fig. 9.

Up to $24.8 \%$ of the PM losses can be deducted, whilst sacrificing only $4.7 \%$ of the output power when implementing a $4.6 \mathrm{~mm}$ tip-based shaping. For the centric based approach, the losses show a similar trend to the tip based shaping, as shown in Fig. 10. Yet, the torque ripple performance in the centric method has lower values.

\section{E. Study E: Semi-Magnetic Wedges}

SM-Ws can have a relative permeability ranging from approximately 2 to 20 [13]. For this study, it is fixed at 10, and four different geometry variations are investigated, as demonstrated in both Table II and Fig. 11. It can be noted that a very slight increase in the copper loss is experienced, as shown in Fig. 12, due to the smaller copper area substituted for accommodating the slot wedges. Apart from this minor drawback, the PM losses can be halved by both E1 \& E4 designs. A corresponding increase in efficiency is also reported. Although an improper use of SM-Ws can lead to increase the leakage fluxes [14]. Also the output power and torque ripple remain roughly constant.

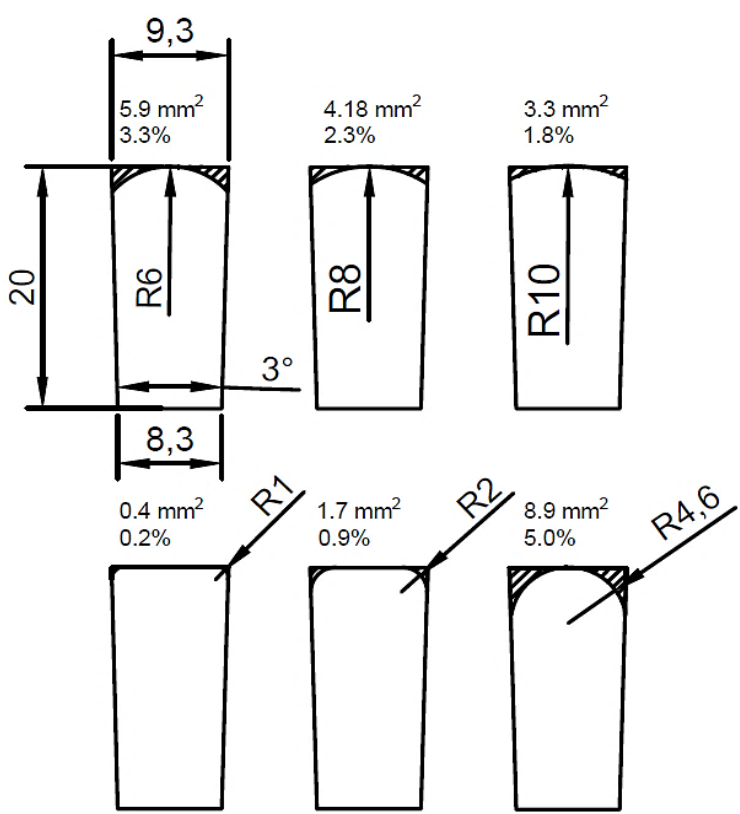

Fig. 9 PM tips shaping dimensions.

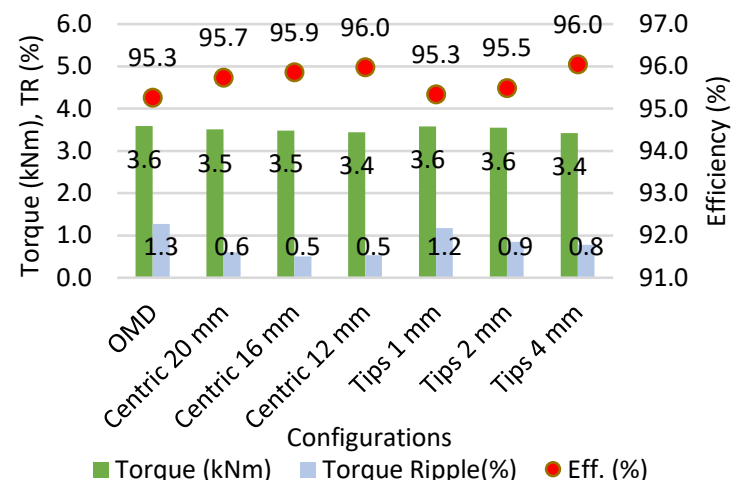

a)

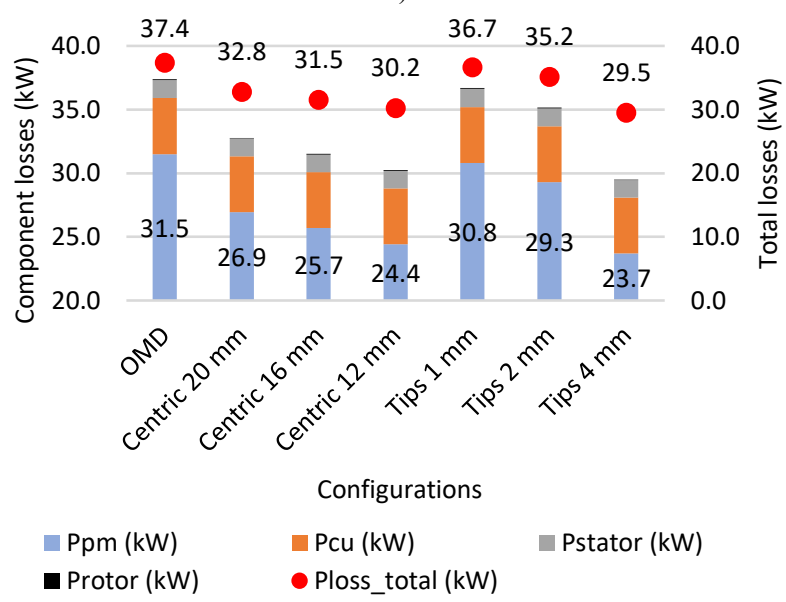

b)

Fig. 10 Study D, a) main performance features, b) losses breakdown. TABLE II

MODIFIED SEMI-MAGNETIC SLOT WEDGE GEOMETRY

\begin{tabular}{c|ccc}
\multicolumn{1}{l}{} & $\mathbf{d}_{\mathbf{1}}(\mathbf{m m})$ & $\mathbf{d}_{\mathbf{2}}(\mathbf{m m})$ & $\mathbf{d}_{\mathbf{3}}(\mathbf{m m})$ \\
\hline Design E1 & 0.5 & 0.5 & 0.5 \\
Design E2 & 0.5 & 1 & 1 \\
Design E3 & 1 & 0.5 & 0.5 \\
Design E4 & 1 & 1 & 1
\end{tabular}




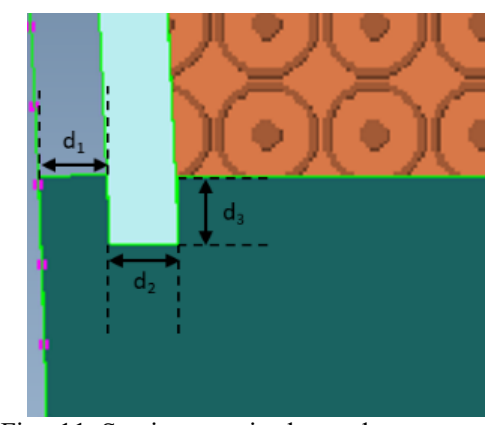

Fig. 11 Semi-magnetic slot wedge geometry.

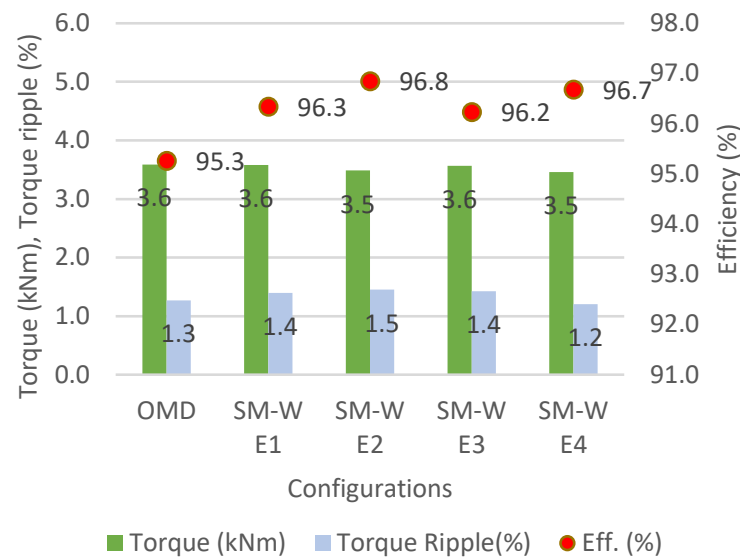

a)

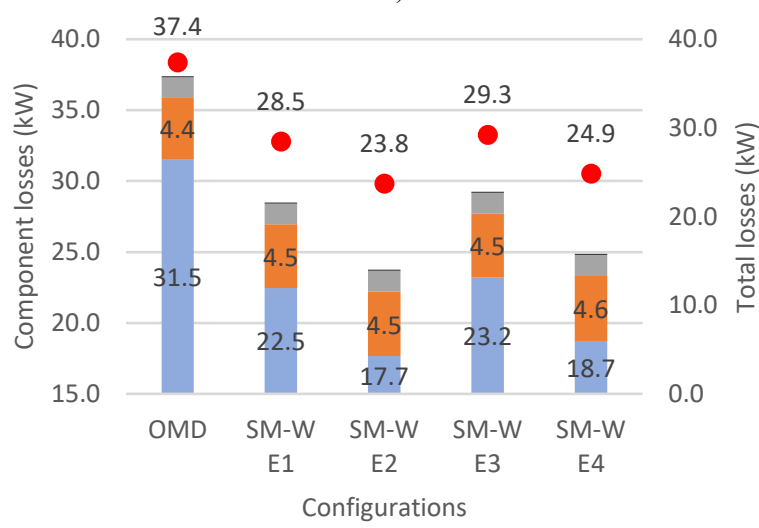

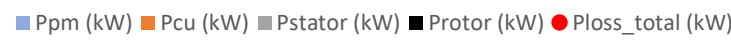

b)

Fig. 12 Study E, a) main performance features, b) loss breakdown.

\section{COMBINED EFFECTS AND FInAL DESIGN}

It can be concluded that each technique has some advantages and disadvantages. Combining a number of these strategies could result in a more appealing, improved performance and efficient design.

The tangential segmentation proved to be generally less beneficial for this application, and will not be adopted. A good combination of strategies is selecting a motor featuring 20 axial PM segments, $0.95 \mathrm{Spm}$ with radial edges, $20 \mathrm{~mm}$ centric-tip-based shaping and the 'E1' semimagnetic slot wedge design.

This "best" motor has an efficiency of $98.4 \%$ against $95.3 \%$ of OMD, a lower torque ripple of $0.6 \%$, a reduced weight by $1.7 \mathrm{~kg}$, that is $6.3 \%$ less PM material used, and the PM losses are only $20 \%$ of the OMD level. Table III at the end of the paper - summarises all of the studied designs and solutions, thus providing the reader of more in-depth analysis of the proposed techniques. Additionally, in Table III a column to evaluate the cost index is added to estimate both manufacturing and assembly costs associated to each design.

\section{CONCLUSIONS}

This paper discussed five different ways to mitigate PM eddy current losses in Halbach array-based motors. Each study presented a different way of shaping the PM so that the losses are minimised.

Tangential segmentation is not advised for this type of motor, as it yields no measurable benefits. Axial segmentation proved to be one of the most effective methods. Yet, for a motor with 30 poles and a total of 120 segments in the whole HBA, it can be complex and expensive to implement a high number of segments. Therefore, although there are available performance gains, such as improved output power, average torque and efficiency, the economic and complex assembly costs must be considered. Reducing the pole arc angle has two advantages; firstly there is less material used i.e. lower purchase cost and machine mass, and secondly the small space created between the segments aids the assembly process. In addition, the losses can be lowered by an acceptable margin - up to $50 \%$ - and the performance improved with a span angle near unity. Shaping the PMtips can be double-edged. On the one hand, less material is used the torque ripple is improved, and losses are moderately reduced, but on the other hand manufacturing costs increase. Finally, semi-magnetic slot wedges are an attractive concept which can improve the overall performance of this motor, for instance efficiency increase by $1.5 \%$ and PM loss reduced by $56.2 \%$, with an acceptable level of modifications to the stator slots.

\section{REFERENCES}

M. Lukic, P. Giangrande, A. Hebala, S. Nuzzo, and M. Galea, "Review, Challenges and Future Developments of Electric Taxiing Systems," IEEE Trans. Transp. Electrif., vol. PP, no. c, p. 1, 2019.

[2] A. K. Jha, L. Garbuio, A. Kedous-Lebouc, J. P. Yonnet, and J. M. Dubus, "Design and comparison of outer rotor bonded magnets Halbach motor with different topologies," 2017 15th Int. Conf. Electr. Mach. Drives Power Syst. ELMA 2017 - Proc., pp. 6-10, 2017.

[3] W. A. M. Ghoneim, A. Hebala, and H. A. Ashour, "Sensitivity Analysis of Parameters Affecting the Performance of Radial Flux Low-Speed PMSG," in Proceedings - 2018 23rd International Conference on Electrical Machines, ICEM 2018, 2018, pp. 968-974.

[4] K. Liu, M. Yin, W. Hua, Z. Ma, M. Lin, and Y. Kong, "Design and analysis of halbach ironless flywheel BLDC motor/generators," IEEE Trans. Magn., vol. 54, no. 11, pp. 1-5, 2018.

[5] A. Hebala, W. A. M. Ghoneim, and H. A. Ashour, "Detailed Design Procedures for Low-Speed, SmallScale, PMSG Direct-Driven by Wind Turbines," in 2018 XIII International Conference on Electrical 
Machines (ICEM), Alexandroupoli, 2018, vol. 14, no. 1, pp. 697-703.

[6] M. Galea, T. Hamiti, and C. Gerada, "Torque density improvements for high performance machines," Proc. 2013 IEEE Int. Electr. Mach. Drives Conf. IEMDC 2013, pp. 1066-1073, 2013.

[7] I. M. Ocana, N. J. Baker, B. C. Mecrow, C. Hilton, and S. Brockway, "Halbach array for an in-wheel traction motor," Proc. - 2018 23rd Int. Conf. Electr. Mach. ICEM 2018, pp. 231-237, 2018.

[8] J. Luo, C. Zhao, X. Zhang, J. Sun, and Q. Zeng, “An outer-rotor traction machine with halbach magnetized permanent magnets and concentrated fractional slot windings," IEEE Transp. Electrif. Conf. Expo, ITEC Asia-Pacific 2014 - Conf. Proc., pp. 1-4, 2014.

[9] "Magnix Aero." [Online]. Available: https://www.magnix.aero/. [Accessed: 30-Oct-2019].

[10] A. Hebala et al., "Feasibility Design Study of HighPerformance, High-Power-Density Propulsion Motor for Middle-Range Electric Aircraft," in 29th IEEE International Symposium on Industrial Electronics 1719 June 2020, online conference hosted in Delft, The
Netherlands [Accepted/Presented].

[11] S. Nuzzo, P. Bolognesi, G. Decuzzi, P. Giangrande, and M. Galea, "A Consequent-Pole Hybrid Exciter for Synchronous Generators," IEEE Trans. Energy Convers., pp. 1-1, 2020.

[12] S. Ruoho, T. Santa-nokki, J. Kolehmainen, and A. Arkkio, "Modeling Magnet Length In 2-D FiniteElement Analysis of Electric Machines," IEEE Trans. Magn., vol. 45, no. 8, pp. 3114-3120, 2009.

[13] S. Nuzzo, M. Degano, M. Galea, C. Gerada, D. Gerada, and N. Brown, "Improved Damper Cage Design for Salient-Pole Synchronous Generators," IEEE Trans. Ind. Electron., vol. 64, no. 3, pp. 1958-1970, Mar. 2017.

[14] N. L. Brown, S. Nuzzo, M. Galea, C. Gerada, D. Gerada, and A. Mebarki, "Damper cage loss reduction and noload voltage THD improvements in salient-pole synchronous generators," in 8th IET International Conference on Power Electronics, Machines and Drives (PEMD 2016), Glasgow, 2016, 2016, pp. 7 .-7 .

TABLE III

SUMMARY OF ALL THE STUDIED DESIGNS AND SOLUTIONS

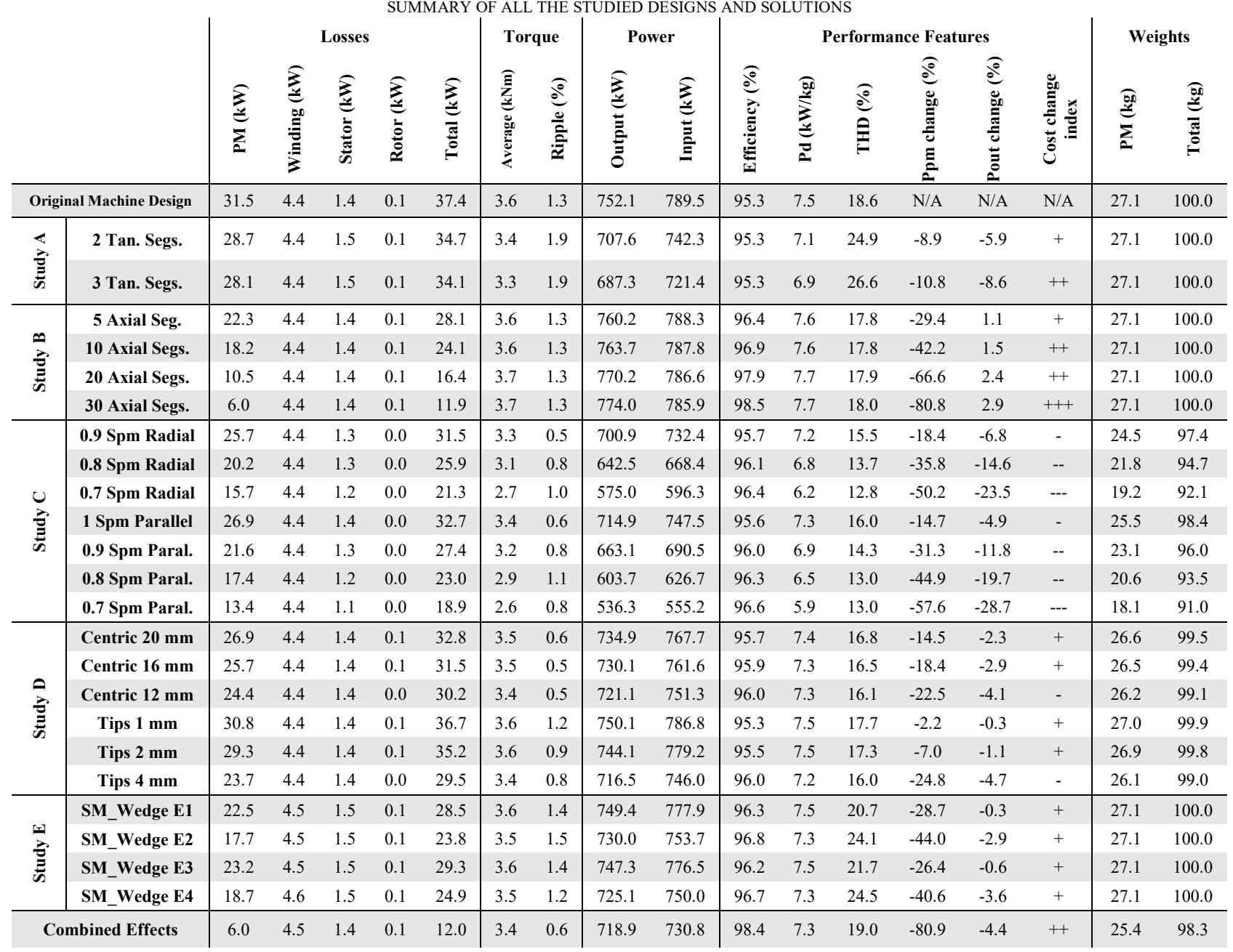

